\title{
Outbreak of Seoul virus among rats and rat owners - United States and Canada, 2017
}

\author{
JL Kerins ${ }^{1,2 *}$, SE Koske ${ }^{3}$, J Kazmierczak³, C Austin 4 , K Gowdy5, A Dibernardo ${ }^{6}$, Seoul Virus Working \\ Group, Canadian Seoul Virus Investigation Group (Federal), Canadian Seoul Virus Investigation \\ Group (Provincial)+
}

\section{Summary}

\section{What is already known about this topic?}

Seoul virus, a type of hantavirus, is carried by Norway rats. Humans become infected through contact with virus shed in rat urine or droppings, or inhalation of virus particles in dust from contaminated bedding. Infected rats do not develop disease, but humans can experience symptoms ranging from mild influenza-like illness to severe disease with kidney failure and death. Although infections have been previously reported in humans after contact with wild rats, Seoul virus infections had not been reported in pet rats in the United States or Canada.

\section{What is added by this report?}

This report describes the first known outbreak of Seoul virus infections in humans from contact with pet rats in the United States and Canada. This investigation identified 31 United States facilities with human and/or rat Seoul virus infections in 11 states, including six that exchanged rats with Canadian ratteries. Seventeen persons had recent infection with Seoul virus, eight became ill, and three were hospitalized and recovered.

\section{What are the implications for public health practice?}

Human hantavirus infections are reportable to state or local health departments in the United States. Clinicians should consider Seoul virus infection in patients with a history of rat contact and compatible symptoms. Pet rat owners and breeders should also be aware of Seoul virus and should practice good hand hygiene and safe rodent handling to prevent infection.

\author{
Affiliations \\ ${ }^{1}$ Epidemic Intelligence Service, \\ Centers for Disease Control and \\ Prevention (CDC), Atlanta, GA \\ ${ }^{2}$ Chicago Department of Public \\ Health, Chicago, IL \\ ${ }^{3}$ Wisconsin Department of Health \\ Services, Madison, WI \\ ${ }^{4}$ Illinois Department of Public \\ Health, Springfield, IL \\ ${ }_{5}^{5}$ Population and Public Health \\ Division, Ontario Ministry of \\ Health and Long-Term Care, \\ Toronto, ON \\ ${ }^{6}$ National Microbiology \\ Laboratory, Public Health Agency \\ of Canada, Winnipeg, MB \\ ${ }^{\dagger}$ This paper is identical in \\ content to the primary article \\ published in the Morbidity and \\ Mortality Weekly Report (MMWR) \\ and released electronically on \\ February 1, 2018 having met \\ the guidelines for simultaneous \\ publication as set forth by the \\ International Committee of \\ Medical Journal Editors (www. \\ icmje.org).
} Outbreak of Seoul virus among rats and rat owners - United States and Canada, 2017. Can Dis Commun Rep. 2018;44(2): 71-4. https://doi.org/10.14745/ccdr.v44i02a07

\section{Introduction}

In December 2016, the Wisconsin Department of Health Services (WDHS) notified Centers for Disease Control and Prevention (CDC) of a patient hospitalized with fever, leukopenia, elevated transaminases, and proteinuria. The patient owned and operated an in-home rattery, or rat-breeding facility, with approximately 100 Norway rats, primarily bred as pets. A family member developed similar symptoms four weeks later, but was not hospitalized. Because both patients were known to have rodent contact, they were tested for hantavirus infections. In January 2017, CDC confirmed recent, acute Seoul virus infection in both patients. An investigation was conducted to identify additional human and rat infections and prevent further transmission. Ultimately, the investigation identified 31 facilities in 11 states with human and/or rat Seoul virus infections; six facilities also reported exchanging rats with Canadian ratteries. Testing of serum samples from 183 persons in the United States (US) and Canada identified 24 (13.1\%) with Seoul virus antibodies; three $(12.5 \%)$ were hospitalized, and no deaths occurred. This investigation, including cases described in a previously published report from Tennessee (1), identified the first known transmission of Seoul virus from pet rats to humans in the US and Canada. Pet rat owners should practice safe rodent handling to prevent Seoul virus infection (2).

Seoul virus is an Old World hantavirus in the Bunyaviridae family. Its natural reservoir is the Norway rat (Rattus norvegicus). Rats infected with Seoul virus are asymptomatic, but can transmit the virus to humans through infectious saliva, urine, droppings, or aerosolization from contaminated bedding. Human signs and symptoms range from mild influenza-like illness to hemorrhagic fever with renal syndrome (HFRS). HFRS causes acute renal failure and can result in death; however, asymptomatic Seoul virus infections also occur. Wild Norway rats in the US have been known to harbour Seoul virus infection (3), but transmission to humans is rare (4). Seoul virus is not known to spread 
from person to person. In the United Kingdom, Seoul virus transmission has occurred from pet rats to humans (5), but before this outbreak, infections had not been reported in pet rats in the US or Canada.

\section{Investigation and results}

After confirming Seoul virus infection in the Wisconsin patients, CDC and WDHS initiated investigations into rat shipments to (trace-back) and from (trace-forward) the rattery to identify suspected and confirmed facilities. Trace-back investigations initially extended back two months prior to onset of clinical disease, based on the known maximum incubation period for Seoul virus in humans. As additional confirmed facilities were identified, tracing focused instead on interactions with known infected facilities, sometimes as much as one year prior. Suspected facilities included ratteries, homes, or pet stores that sold rats to a confirmed facility (a facility where at least one human or rat tested positive for Seoul virus infection) or housed rats that lived at or comingled with rats from a confirmed facility. Once a suspected facility was identified, local or state health officials interviewed persons with a history of rodent contact associated with the facility about their rat exposure and health history. Additionally, the primary rodent caretaker was interviewed using a standardized questionnaire to identify movement of rats into and out of the facility, including dates and locations where the rats were obtained. Local or state health officials offered laboratory testing for Seoul virus infection to all persons with rodent contact. Officials recommended testing for persons with a history of febrile illness and exposure to rats from a confirmed facility and for rats at suspected and confirmed facilities. Trace-forward and trace-back investigations of rat shipments at confirmed facilities identified additional suspected facilities, which were similarly assessed.

A suspected human case of Seoul virus infection was defined as a febrile illness (recorded temperature $>101^{\circ} \mathrm{F}\left[38.3^{\circ} \mathrm{C}\right]$ or subjective history of fever) or an illness clinically compatible with Seoul virus infection (myalgia, headache, renal failure, conjunctival redness, thrombocytopenia, or proteinuria) without laboratory confirmation in a person reporting contact with rats from a confirmed or suspected facility. Human Seoul virus infections were laboratory-confirmed by detection of Seoul virus-specific immunoglobulin $\mathrm{M}$ (IgM) and/or immunoglobulin $\mathrm{G}(\mathrm{lgG})(6)$ antibodies by enzyme-linked immunosorbent assay (ELISA). In the US, Seoul virus infections in rats were confirmed through detection of viral RNA by reverse transcriptionpolymerase chain reaction (RT-PCR) and/or IgG ELISA at CDC, or by CDC-validated commercial IgG testing. In Canada, public health officials investigated rat breeding facilities that exported rats to and imported rats from affected US facilities. Seoul virus infection was detected in Canadian rats from breeding facilities using the same serologic and molecular-based protocols described for US facilities.

By March 16, 2017, trace-forward and trace-back investigations identified approximately 100 suspected facilities in 21 states. Among these, 31 facilities in 11 states had laboratory-confirmed human or rat infections, including a previously reported household in Tennessee with two confirmed human infections (1). Six confirmed facilities in six states (Georgia, Illinois, Missouri,
South Carolina, Tennessee, and Utah) reported exchanging rats with Canadian ratteries during their trace-forward and trace-back investigations. A total of 163 persons in the US and 20 in Canada consented to serologic testing; 17 (10.4\%) US residents and one (5.0\%) Canadian resident had detectable $\operatorname{lgM}$ and $\operatorname{lgG}$ antibodies, indicating recent infection, and four (2.5\%) US residents and two (10.0\%) Canadian residents had only lgG antibodies, indicating past or convalescent infection. Among the 17 US patients with recent Seoul virus infection, eight reported recent febrile illness. Three were hospitalized, but did not develop HFRS, and all recovered. Serious illness was not reported in any Canadian patients. All strains detected in Canada and the US were indistinguishable from one another based on nucleotide sequencing (7), indicating that a single strain was responsible for the outbreak. No single facility was identified as the origin of the outbreak.

\section{Public health response}

On January 24, CDC issued a Health Alert Notice to notify health departments and health care providers of the Seoul virus investigations. On February 10, the World Health Organization was notified of the US and Canadian infections and investigations as required by International Health Regulations. On January 31 and May 9, 2017, CDC and the Pet Industry Joint Advisory Council hosted calls to provide updates on the Seoul virus outbreak and to answer questions for the pet industry and fancy rat community. The CDC created a website with Seoul virus facts and frequently asked questions for the public.

Health departments notified suspected and confirmed facilities, and placed those facilities under quarantine, allowing no rats to enter or leave. Rat contact was limited to as few persons as possible to reduce transmission. In suspected facilities, CDC recommended rat testing be performed under the supervision of a public health official or licensed veterinarian. The quarantine was lifted when at least four weeks had elapsed since the newest animal was introduced, and all rats subsequently tested negative. Rats belonging to owners who refused to test their animals could remain quarantined for life or be euthanized. The CDC recommended euthanasia of all rats in confirmed facilities as the most effective method to prevent transmission, although control recommendations differed by state and country according to local policies and response capacities. If euthanasia was not possible, then owners could either quarantine all rats for life or pursue quarantine with testing and culling. The testing and culling strategy entailed testing all rats and euthanizing only infected rats. Testing and euthanasia were repeated at four week intervals until all rats tested negative and the quarantine was lifted. In Canada, public health officials opted for education and a voluntary testing and culling approach to control Seoul virus transmission.

\section{Discussion}

This outbreak report, in parallel to the previously described investigation in Tennessee (1), describes the first known cases of Seoul virus infection in humans attributable to contact with pet rats in the US and Canada. Human hantavirus infections 
are nationally notifiable in the US and suspected cases should be reported to state or local health departments. Health care providers should consider Seoul virus infection in patients with febrile illness who report rat exposure; CDC recommends testing for any person with compatible illness and rodent contact. Testing is available at CDC and through some state and commercial laboratories. In Canada, testing is available for symptomatic persons with rat exposure, rattery owners associated with this investigation, and their rats through public health laboratories; for individually owned pet rats and ratteries not associated with the investigation, testing is available through a commercial laboratory.

Pet rat owners should be aware of the potential for Seoul virus infection. To keep themselves and their pets healthy, all persons with rodent contact should avoid bites or scratches and practice good hand hygiene, especially children and persons with compromised immune systems (2). The CDC recommends hand washing after caring for rodents and before eating, drinking, or preparing food (2). If a pet rat is suspected of having Seoul virus, the person cleaning the rodent environment should wear a respirator, gloves, and cover any scratches or open wounds (8). An adult should routinely disinfect rat cages and accessories, including used bedding, with a $10 \%$ bleach solution or a commercial disinfectant (8). More information about rodent contact and disease prevention is available from $\operatorname{CDC}(8,9)$.

Rattery owners are encouraged to quarantine any newly acquired rats for four weeks and to test these rats for Seoul virus antibodies before allowing them to comingle with other rats. Commercial laboratories can perform Seoul virus testing of rodent blood samples, and comparisons of results from shared samples have been concordant with CDC's ELISA and RT-PCR assays. To prevent transmission to humans, CDC recommends euthanasia of all rats in facilities with human or rat Seoul virus infections. Further guidance on methods to eradicate Seoul virus from infected ratteries should be obtained from local or state health departments.

\section{Conflict of Interest}

No conflicts of interest were reported.

\section{Contributors}

\section{Seoul Virus Working Group}

Jan Achenbach, Chester County Department of Health Jill Baber, North Dakota Department of Health

Gary Balsamo, Louisiana Department of Health

Casey Barton Behravesh, CDC

David Blythe, Maryland Department of Health and Mental Hygiene

Iwona Boraks-Pielechaty, Pennsylvania Department of Health; Shelley M. Brown, CDC

Jennifer Brown, Indiana State Department of Health Robert Brucker, Montgomery County Health Department Barbara A. Bruen, Pennsylvania Department of Health Colin Campbell, New Jersey Department of Health Deborah Cannon, CDC

Beth Carlson, North Dakota Department of Agriculture
Kris Carter, CDC, Idaho Department of Health and Welfare Cynthia Cary, CDC

Caroline Castillo, CDC, Michigan Department of Health and Human Services

Cheng-Feng Chiang, CDC

Mary Choi, CDC

Ellen Christel, Manitowoc County Health Department

April Clayton, CDC

Leah Colton, Colorado Department of Public Health and

Environment

Laura Cronquist, North Dakota Department of Health

David Damsker, Bucks County Health Department

William G. Davis, CDC

Annabelle de St Maurice, CDC

Jordan Dieckman, Wisconsin Department of Health Services John Dunn, Tennessee Department of Health

Drew D. Dycus, Bucks County Health Department

Elizabeth Ervin, CDC

Michelle Feist, North Dakota Department of Health

Amanda Feldpausch, Georgia Department of Public Health Mary Margaret Fill, CDC, Tennessee Department of Health Julie Gabel, Georgia Department of Public Health

Ann Garvey, lowa Department of Public Health

Sarah Genzer, CDC; Suzanne Gibbons-Burgener, Wisconsin Department of Health Services

James Graziano, CDC

Victoria Hall, CDC, Minnesota Department of Health

Russel Heisey, Pennsylvania Department of Health

Heather Henderson, Tennessee Department of Health

Janemarie Hennebelle, Georgia Department of Agriculture Leslie Hiber, Minnesota Department of Health

Stacy Holzbauer, CDC, Minnesota Department of Health Jennifer House, Colorado Department of Public Health and Environment

Eddie Jackson, CDC

Mary H. Jenks, CDC

Dee Jones, Alabama Department of Public Health

Susan Keller, North Dakota Department of Agriculture

John D. Klena, CDC

Rachel F. Klos, Wisconsin Department of Health Services

Barbara Knust, CDC

Anna Kocharian, Wisconsin Department of Health Services

Katrin Kohl, CDC

Gregory Langham, CDC

George Lathrop, CDC

Jennifer Layden, Illinois Department of Public Health

Kathryn Lehatto, Pennsylvania Department of Health Jodi Lovejoy, Indiana State Board of Animal Health

Kenneth Lowery, Georgia Department of Public Health

Nicole Lukovsky-Akhsanov, CDC

Nhiem Luong, Delaware Health and Social Services

Michael Maglio, Chester County Department of Health

Craig Manning, CDC

Chandra Marriott, Pennsylvania Department of Health

Natalie Marzec, Colorado Department of Public Health and Environment

Michel Masters, Montgomery County Health Department Susan McClanahan, Minnesota Board of Animal Health Lisa McCloskey, Bucks County Health Department Shannon McKnight, Pennsylvania Department of Health Jennifer McQuiston, CDC

Sara McReynolds, North Dakota Department of Agriculture Gianna Megaro, Chester County Department of Health 
Maria Morales-Betoulle, CDC

Allyn K. Nakashima, Utah Department of Health

Stuart Nichol, CDC

Julie Paoline, Montgomery County Health Department

Nishi Patel, CDC

Ketan Patel, CDC

Dallin Peterson, Utah Department of Health

Leah Posivak-Khouly, Montgomery County Health Department

Nathaniel Powell Jr., CDC

Howard Pue, Missouri Department of Health \& Senior Services

Lawrence Purpura, CDC

Rachel Radcliffe, South Carolina Department of Health \&

Environmental Control

Nicole Reynolds, Minneapolis Medical Research Foundation

Linda Roesch, CDC

Pierre Rollin, CDC

Andrea L. Sandberg, Brown County Health and Human Services Joni Scheftel, Minnesota Department of Health

Betsy Schroeder, CDC, Indiana State Department of Health

Irshad A. Shaikh, Montgomery County Department

Trevor Shoemaker, CDC

Jennifer Sidge, Michigan Department of Health and Human

Services

Tom Sidwa, Texas Department of State Health Services

Kim Signs, Michigan Department of Health and Human Services

Amber Singh, Ohio Department of Health

Aaron Smee, Pennsylvania Department of Health

Danielle Stanek, Florida Department of Health

Mary Grace Stobierski, Michigan Department of Health and

Human Services

Anne Straily, CDC

Ute Ströher, CDC

Cassandra Tansey, CDC

Leslie Tengelsen, Idaho Department of Health and Welfare

Beth Thompson, Minnesota Board of Animal Health

Susan L. Ward, Bucks County Department of Health

Kimberly Warren, Pennsylvania Department of Health

Susan Weinstein, Arkansas Department of Health

Deborah Weiss, CDC, Wisconsin Department of Health Services

Andre Weltman, Pennsylvania Department of Health

Tigist Yirko, Pennsylvania Department of Health

Joyce Zuzack, Bucks County Department of Health

\section{Canadian Seoul Virus Investigation Group (Federal)}

Peter A. Buck, Public Health Agency of Canada (PHAC)

Allen Grolla, PHAC

Chris Huynh, PHAC

L. Robbin Lindsay, PHAC

Courtney Loomer, PHAC

David Safronetz, PHAC

Angela Sloan, PHAC

Jim E. Strong, PHAC

Joanne R. Tataryn, PHAC

Linda Vrbova, PHAC

\section{Canadian Seoul Virus Investigation Group (Provincial)}

Office of the Chief Medical Officer of Health

Ontario Ministry of Agriculture, Food and Rural Affairs

Population and Public Health Division, Ministry of Health and

Long-Term Care

Public Health Ontario

Ontario Public Health Units

\section{References}

1. Fill MA, Mullins H, May AS, et al. Notes from the Field: Multiple Cases of Seoul Virus Infection in a Household with Infected Pet Rats - Tennessee, December 2016-April 2017. MMWR Morb Mortal Wkly Rep 2017;66:1081-2. DOI (https:// doi.org/10.15585/mmwr.mm6640a4). PubMed (https://www. ncbi.nlm.nih.gov/entrez/query.fcgi?cmd=Retrieve\&db=PubM ed\&list_uids=29023435\&dopt=Abstract ) .

2. Centers for Disease Control and Prevention. Key Messages about Pet Rodents. January 19, 2017. Atlanta, GA: US Department of Health and Human Services, Centers for Disease Control and Prevention; 2017. https://www.cdc.gov/ healthypets/pets/small-mammals/petrodents.html

3. Childs JE, Korch GW, Smith GA, Terry AD, Leduc JW. Geographical distribution and age related prevalence of antibody to Hantaan-like virus in rat populations of Baltimore, Maryland, USA. Am J Trop Med Hyg 1985;34:3857. DOI (https://doi.org/10.4269/ajtmh.1985.34.385). PubMed (https://www.ncbi.nlm.nih.gov/entrez/query.fcgi?cmd=Retrie ve\&db=PubMed\&list_uids=3885776\&dopt=Abstract).

4. Knust B, Rollin PE. Twenty-year summary of surveillance for human hantavirus infections, United States. Emerg Infect Dis 2013;19:1934-7 10.3201/eid1912.131217. DOI (https://doi. org/10.3201/eid1912.131217). PubMed (https://www.ncbi. $\mathrm{nlm}$.nih.gov/entrez/query.fcgi?cmd=Retrieve\&db=PubMed\&l ist_uids=24274585\&dopt=Abstract)

5. Jameson LJ, Taori SK, Atkinson B, et al. Pet rats as a source of hantavirus in England and Wales, 2013. Euro Surveill 2013;18:20415. PubMed (https://www.ncbi.nlm. nih.gov/entrez/query.fcgi?cmd=Retrieve \&db=PubMed\&li st_uids=23470018\&dopt=Abstract).

6. Ksiazek TG, West CP, Rollin PE, Jahrling PB, Peters CJ. ELISA for the detection of antibodies to Ebola viruses. J Infect Dis 1999;179(Suppl 1):S192-8. DOI (https://doi. org/10.1086/514313). PubMed (https://www.ncbi.nlm.nih. gov/entrez/query.fcgi?cmd=Retrieve $\& \mathrm{db}=$ PubMed\&lis t_uids=9988184\&dopt=Abstract).

7. Woods C, Palekar R, Kim P, et al. Domestically acquired seoul virus causing hemorrhagic fever with renal syndrome-Maryland, 2008. Clin Infect Dis 2009;49:e109-12. DOI (https://doi.org/10.1086/644742). PubMed (https:// www.ncbi.nlm.nih.gov/entrez/query.fcgi?cmd=Retrieve\&db= PubMed\&list_uids=19848600\&dopt=Abstract).

8. Centers for Disease Control and Prevention. Cleaning Up After Pet Rodents to Reduce the Risk of Seoul Virus Infection. January 19, 2017. Atlanta, GA: US Department of Health and Human Services, Centers for Disease Control and Prevention; 2017. https://www.cdc.gov/hantavirus/outbreaks/seoul-virus/ cleaning-up-pet-rodents.html

9. Centers for Disease Control and Prevention. Healthy Pets Healthy People. April 5, 2017. Atlanta, GA: US Department of Health and Human Services, Centers for Disease Control and Prevention; 2017. https://www.cdc.gov/healthypets/ 